\title{
Spoilage volatiles and sensory properties of a grilled stick meat product inoculated with Pediococcus acidilactici FLE07 as starter culture
}

\author{
Olusegun A. Olaoye
}

\author{
Department of Food Science and Technology, Michael Okpara University of \\ Agriculture, Umudike, Abia State, Nigeria
}

Keywords:
Meat
Grill
Pediococcus
acidilactici
Spoilage
Volatile
Sensory

Article history:

Received 12.06.2016 Received in revised form 23.08.2016 Accepted 01.09.2016

\section{Corresponding author:}

Olusegun A. Olaoye E-mail: olaayosegun@ yahoo.com

\section{Abstract}

Introduction. Grilled meat products are normally eaten as snacks in many developed and developing countries usually during leisure. The use of biological agents such as lactic acid bacteria may help improve the associated volatiles and sensory appeal of such products.

Materials and methods. A grilled meat product (Tsire) was inoculated with $6 \log$ CFU/g of Pediococcus acidilactici FLE07 as starter culture (IS), with the objective of improving the associated spoilage volatiles during a 4 day storage at $30^{\circ} \mathrm{C}$; while uninoculated sample of Tsire served as control (UC). Solid phase mass extraction gas chromatography-mass spectrometry (SPME-GCMS) and taste panel using hedonic scaling were used to evaluate the volatiles and sensory quality respectively during storage.

Results and discussion. In preliminary experiments, ten Pediococcus strains were evaluated for production of organic acids; among these, $34 \mathrm{~g}_{\text {acid }} / 10^{7} \mathrm{CFU}$ was recorded as highest lactic acid production by $P$. acidilactici FLE07 and was chosen as starter culture for inoculation of Tsire. The strain was shown to produce acetic acid of concentration lower than $12 \mathrm{~g}_{\text {acid }} / 10^{7} \mathrm{CFU}$. SPME-GCMS analysis of the grilled meat product showed that a total of fourty eight (48) volatiles, belonging to ketones $(35.42 \%)$, acids $(8.33 \%)$, alcohols $(25 \%)$, aromatic/cyclic $(14.58 \%)$ and nitrogenous compounds (16.67\%), were detected during storage. Volatiles including acetone, 2-butanone, 2,3-butanedione, 3-hydroxy-2-butanone, 2-hexanone, 2-heptanone and 1-hydroxy2-propanone were among the prominent ketone compounds observed in the Tsire samples, and their total are units (TAUs) showed significant difference $(p<0.05)$ between the IS and UC samples. There was reduction in spoilage volatile indicators; concentrations $(\mu \mathrm{g} / \mathrm{g})$ of $0.57,1.98,0.93$ and 1.39 were recorded for heptanal, 1-octen-3-ol, 3-methyl-butanoic acid and nonanal respectively in inoculated samples (IS) compared to 2.43, 3.21, 2.94 and 2.94 obtained for uninoculated control (UC) on day 3. Sensory study with the use of 50 panelists to provide data showed that higher scores $(p<0.05)$ were recorded in the aroma, appearance, tenderness, taste and general acceptability properties of IS than UC.

Conclusion. It was concluded that Pediococcus acidilactici FLE07 and other suitable starter culture(s) may be used in promoting sensory quality development and availability of the product beyond the day of production. This is the first report of this type on the grilled meat product. 


\section{Introduction}

Grilled meat products are normally prepared by grilling of shredded meat cuts hanged on sharpened edges of sticks, and Tsire is common example in Nigeria. The meat cuts are normally spiced with peanut cake, spices, vegetable oil, salt or other flavorings and then cooked by grilling. They are sprinkled with groundnut oil during the grilling process to simulate the traditional technique of avoiding burning or charring [1]; grilling is usually carried out around glowing charcoals. Tsire could be prepared from muscles of beef, goat, mutton or chicken, though preparation from beef is common [2]. It is a popular traditional meat product in Nigeria commonly eaten as delicacies, served or sold along streets or in club houses.

Cooking of meat involves a complex series of thermally induced reactions occurring between non-volatile components of lean and fatty tissues, resulting in a large number of reaction products (Lorenzo et al., 2016); the volatile compounds formed in these reactions are largely responsible for the characteristic flavour of cooked meat [1]. Such products include aldehydes, carboxylic acids, alcohols, ketones, esters, sulfur compounds, nitrogenous compounds, terpenes, alkanes and alkenes, aromatic and cyclic hydrocarbons, which have been noted to contribute to flavour development in meat products [3].

Pediococcus is a genus under the group of lactic acid bacteria (LAB) which play positive role in fermentation and preservation of many foods, especially by their abilities to produce considerable amounts of volatile and organic compounds [2]. LAB have a generally regarded as safe (GRAS) status and have been widely used as starters in the industrial preservation of meats [4]. For instance, Olaoye et al. [5] reported the application of LAB cultures, P. pentosaceus GOAT 01 and Lactobacillus plantarum GOAT012, in the preservation of goat meat during storage at $30^{\circ} \mathrm{C}$. According to the authors, the LAB cultures were able to extend the shelf life of the meat for days beyond the uninoculated control samples. In another study, the use of Pediococcus cultures in the generation of antioxidant nitrogen compounds in Iberian dry-fermented sausages was reported by Fernández et al. [6]. Moreover, Lorenzo et al. [7] investigated the effect of commercial cultures of Pediococcus spp. on volatile compound profile and sensory characteristics of dry - cured foal sausage during ripening. Olaoye [1] and Olaoye [3] reported studies on the effect of storage period on volatiles and consumers' acceptability of Tsire and pork balangu (a grilled meat product) respectively; the authors recommended that inoculation of the meat product with LAB cultures should be carried out in future studies for possible improvement in volatile characteristics.

In spite of the available reports on meat products, no study is currently available on the effect of LAB cultures on volatiles of Tsire during storage. Hence, the present study focused on evaluating the influence of $P$. acidilactici FLE07 culture on the volatile compounds, especially those that may be spoilage indicators, and sensory characteristics of the traditional meat product during storage.

\section{Materials and methods}

Source of meat and ingredients. The beef used in this study was purchased from a butcher's shop in the city of Nottingham, UK, and conveyed to the laboratory over ice crystals for immediate use. The ingredients used included ground red pepper (Capsicum sp.), onions (Alium cepa), ginger (Zingiber officinalis), groundnut (Arachis hypogaea) and salt, obtained from a Nigerian shop in the same city. 
Sources of LAB used and growth conditions. Ten presumptive LAB isolates, previously isolated and phenotypically identified from meat in a preliminary study were used in the present study [8]. They included Pediococcus pentosaceus LIV01, $P$. acidilactici FLE07, P. acidilactici FLE02, P. pentosaceus INT01, P. pentosaceus INT02, Lactobacillus plantarum FLE04, P. acidilactici INT04, P. acidilactici FLE07, Leuconostoc mesenteroides FLE03 and $P$. pentosaceus INT04. The optimum growth temperature of the isolates in MRS medium (Oxoid, UK) was $30{ }^{\circ} \mathrm{C}$. The isolates were routinely maintained in MRS broth medium containing $20 \%$ glycerol at $-20{ }^{\circ} \mathrm{C}$ as working cultures, and at $-80{ }^{\circ} \mathrm{C}$ for long-term storage.

Production of organic acids. Prior to selection of one of the LAB isolates as starter culture, the isolates were evaluated for their abilities to produce organic acids (lactic and acetic acids), using the method of Olaoye et al. [8]. One of the isolates, P. acidilactici FLE07, showed considerable production of organic acids, and was hence chosen as starter culture for inoculation of the traditional meat product prior to storage. Concentrations of the organic acids were expressed in $\mathrm{g}_{\text {acid }} / 10^{7} \mathrm{CFU}$ (i.e grams of lactic/acetic acid per $10^{7}$ colony forming units)

Confirmation of identity of presumptive $P$. acidilactici FLE07 used as starter culture. The LAB isolate $P$. acidilactici FLE07 used as starter culture was presumptively identified in a previous study [8]. Full identity of the isolate was obtained in the present study using 16S rDNA nucleotide sequencing after successful amplification by PCR. Deoxyribonucleic acid (DNA) was extracted using a boiling method [9]. PCR amplification was performed using the following set of primers [10]: Forward, 5'-CCTACGGGAGGCAGCAG-3' and Reverse, 5'-ATTACCGCGGCTGCTGG-3', targeting approximately $200 \mathrm{bp}$ of $16 \mathrm{~S}$ rDNA gene (V3 region). PCR conditions used were as described by Olaoye et al. [5]. Electrophoresis of the 16S rDNA-PCR products, purification and sequencing were carried out as previously described [5]. The specific nucleotide sequences were subjected to BLAST programme of NCBI (website; http://www.ncbi.nlm.nih.gov/blast/) to determine the homology of the Pediococcus isolate with related genera and species [11].

Preparation of $\boldsymbol{T}$ sire and inoculation with $\boldsymbol{P}$. acidilactici FLE07. Tsire samples were prepared according to the method described by Olaoye [1]. Some of the Tsire samples were inoculated with $6 \log \mathrm{CFU} / \mathrm{g}$ of $P$. acidilactici FLE07 culture according to the method of Olaoye and Dodd [2] while uninoculated samples served as control.

Storage of Tsire. The Tsire samples were wrapped in aluminium foils and stored for four days in a storage cabinet at $30^{\circ} \mathrm{C}$ to represent ambient temperature in Nigeria. Samples were taken daily, in three replicates, for analysis of thiobarbituric acids and volatiles compounds.

Analysis of thiobarbituric acid in Tsire. Thiobarbituric acid (TBA) values were determined for the Tsire samples as described by Olaoye and Onilude [12].

Analysis of volatile compounds in Tsire using solid phase mass extraction-gas chromatography mass spectrometry (SPME-GCMS)

The volatiles in the Tsire samples taken daily during storage were analyzed using SPME-GCMS. This was performed by placing $2 \mathrm{~g}$ of samples in $20 \mathrm{ml}$ headspace vials (22.5 mm x $75.5 \mathrm{~mm}$, Grace Alltech, UK). The vials were sealed with a magnetic cap (20mm diameter, 5mm centre, PTFE/Silicone Liner; Grace Alltech) using a Crimper (Part no 60045 , Alltech Associates Inc., USA) and allowed to equilibrate at room temperature $\left(22{ }^{\circ} \mathrm{C}\right)$ for $30 \mathrm{~min}$ before commencement of analysis. 
A Stableflex fibre coated with 50/30 $\mu \mathrm{m}$ divinylbenzenecarboxen on polydimethylsiloxane bonded to a flexible fused silica core (Supelco, Bellefonte, PA, 16823-0048 USA) was used for the extraction of the flavour volatiles in the headspace of the vials. For volatile sampling, an extraction time of $15 \mathrm{~min}$ at room temperature was used, while desorption time was set to $4 \mathrm{~min}$ at $230^{\circ} \mathrm{C}$.

GCMS was carried out using a Trace GC Ultra gas chromatograph (Thermo Electron Corporation, UK) and a DSQ mass spectrometer (1.4.1 SP3 Thermo Electron Corporation, USA). Samples were injected in splitless mode into the GC with a PAL auto-sampler. Chromatography was carried out with a TRACE GC 2000 series gas chromatograph using a ZB-WAX capillary column (Serial no 162147, Order no 7HG-G007-22, L 30m x I.D. $0.25 \mathrm{~mm} \times \mathrm{df} 1 \mu \mathrm{m}$, USA). Helium was employed as the carrier gas, at a constant pressure of $15 \mathrm{psi}$ and splitless time of $1 \mathrm{~min}$. The oven temperature programme was as follows: an initial temperature of $40^{\circ} \mathrm{C}$ was maintained for $1 \mathrm{~min}$, with ramps $8{ }^{\circ} \mathrm{C} / \mathrm{min}$ to $200^{\circ} \mathrm{C}$ and $10^{\circ} \mathrm{C} / \mathrm{min}$ to a final temperature of $230^{\circ} \mathrm{C}$. Mass spectrometry was performed with a DSQ mass spectrometer. The mass spectrometer was operated in positive ionisation electron impact mode $(\mathrm{EI}+)$ at electron energy of $70 \mathrm{eV}$. The scan time was $0.29 \mathrm{~s}$. Samples for injections into the GC were prepared in three replicates. The detector was operated in scan mode, scanning from $\mathrm{m} / \mathrm{z} 20$ to 210 . Source temperature was $200{ }^{\circ} \mathrm{C}$. The data generated were processed with Xcalibur ${ }^{\mathrm{TM}} 1.4 \mathrm{SR} 1$ (Thermo Electron Corporation) software.

Volatile compounds were identified by comparing their mass spectra with those in the National Institute of Standards and Technology (NIST) mass spectral library and/or by calculation of the retention indices relative to a series of n-alkanes (C5-C19; SigmaAldrich, UK) and matching them with standard compounds and data reported in the literature $[13,14]$. The results were reported as relative abundance expressed as total area counts, TAUs $\left(\times 10^{4}\right)$.

Sensory study. Sensory study was conducted on the Tsire samples that depended on inoculation with or without $P$. acidilactici FLE07 and storage time. Samples were evaluated for the sensory properties of aroma, appearance, tenderness, taste and general acceptability using a 50 member panel $(n=50)$, composing of Nigerians who were already familiar with the product. Freshly prepared Tsire samples were used as reference for comparison of sensory properties of other samples during storage. Panelists were asked to allocate scores to three coded replicates of samples, using a 9-point hedonic scale, from 1-dislike extremely to 9-like extremely. Data obtained were subjected to statistical analysis to determine significant differences among samples.

Statistical data analysis. Results which depended on starter culture and storage time were analyzed according to a completely randomized design with three replicates. The data obtained were subjected to one way analysis of variance (ANOVA) to evaluate the effect of starter culture on the samples. Differences between means were evaluated by Duncan's multiple range test and significant difference was expressed at $p<0.05$. The SPSS statistic programme (version 10.01) was used.

The relationship between the inoculated and uninoculated control samples, storage time and their volatile compounds was evaluated by principal component analysis (PCA) using Xlstat software (ver. 17.3.01.19703; Addinsoft, NY). 


\section{Results and discussion}

In this study, ten LAB isolates previously isolated and presumptively identified from meat in a preliminary study [8], were screened for production of organic acids (lactic and acetic acids), with the objective of selecting suitable candidate(s) as starter culture for possible improvement of volatiles and sensory properties of a Nigerian traditional meat product (Tsire) during storage. Among the ten isolates, Pediococcus pentosaceus LIV01, $P$. acidilactici FLE01, $P$. acidilactici FLE02 and $P$. acidilactici FLE07 produced lactic acid higher than $25 \mathrm{~g}_{\text {acid }} / 10^{7} \mathrm{CFU}$ (Figure 1); however, P. acidilactici FLE07 had the highest production of the acid ( $\left.34 \mathrm{~g}_{\text {acid }} / 10^{7} \mathrm{CFU}\right)$ and was chosen as starter culture for inoculation of Tsire. Acetic acid production by the LAB isolates was generally lower than $12 \mathrm{~g}_{\text {acid }}$ $/ 10^{7} \mathrm{CFU}$.

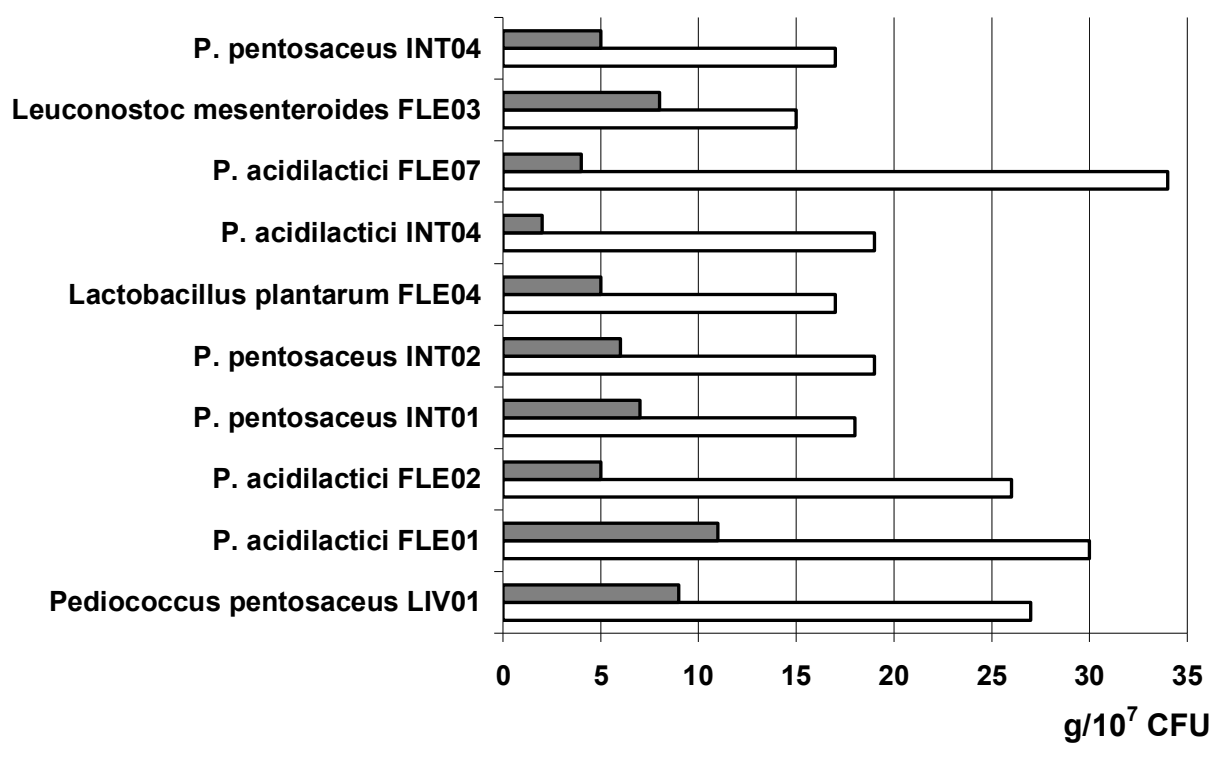

$\square$ lactic acid $\square$ acetic acid

Figure 1. Concentrations of lactic and acetic acids $\left(\mathrm{g}_{\text {acid }} / 10^{7} \mathrm{CFU} / \mathrm{g}\right)$ produced by the LAB isolates

Sixty four (48) volatile compounds were detected in the meat product during storage, and they were categorized into different classes including ketones (class $1 ; 35.42 \%$ ), acids (class 2; 8.33\%), aromatic/cyclic hydrocarbons (class 3; 14.58\%), nitrogenous compounds (class $4 ; 16.67 \%$ ) and alcohols (class 5; 25.0\%); these are presented in Tables 1 and 2.

Similar reports of detection of these classes of volatiles in meat products have been made by other research investigators $[3,15]$.

(In the Table 1: Each value is mean of three replicates of samples; SD1, storage day 1; SD2, storage day 2; SD3, storage day 3; SD4, storage day 4; StdD, standard deviation; P-value, probability value; RI, retention index; MI, method of identification; 1, Identification using authentic standards; 2, Identification using retention indices from the literature and their mass spectra with the NIST mass spectral library) 
Table 1. Total area units $\left(\mathrm{x10}^{4}\right)$ of ketone and acid compounds in Tsire

\begin{tabular}{|c|c|c|c|c|c|c|c|c|c|c|}
\hline \multirow{2}{*}{ Compounds } & \multicolumn{10}{|c|}{ Tsire inoculated with $P$. acidilactici FLE07 } \\
\hline & RI & SD1 & Std & & \begin{tabular}{l|l} 
SD2 & 5 \\
\end{tabular} & StdD & SD3 & StdD & SD4 & StdD \\
\hline \multicolumn{11}{|l|}{ Class 1 - Ketones } \\
\hline Acetone & $<600$ & 5862 & 13 & & 4102 & 129 & 2981 & 172 & 2410 & 74 \\
\hline 3-methyl-2-butanone & $<600$ & 25 & 4 & & 17 & 5 & 25 & 3 & 53 & 12 \\
\hline Methyl-isobutyl-ketone & 612 & 0.79 & 0 & & 2 & 1 & 6 & 2 & 46 & 13 \\
\hline 2-butanone & 618 & 540 & 20 & & 520 & 112 & 605 & 47 & 725 & 129 \\
\hline 2,3-butanedione & 621 & 541 & 64 & & 323 & 32 & 275 & 12 & 172 & 17 \\
\hline 3-methyl-2-pentanone & 634 & 0.11 & 0.0 & & 6 & 2 & 13 & 3 & 68 & 6 \\
\hline 5-methyl-2-hexanone & 687 & 81 & 19 & & 76 & 7 & 69 & 14 & 58 & 10 \\
\hline 2-hexanone & 699 & 24 & 4 & & 20 & 8 & 16 & 2 & 13 & 3 \\
\hline 2,5-hexanedione & 712 & 92 & 12 & & 178 & 36 & 471 & 86 & 1290 & 128 \\
\hline 2-heptanone & 719 & 2 & 0.8 & & 11 & 1 & 19 & 4 & 50 & 3 \\
\hline 2-octanone & 720 & 5 & 3 & & 11 & 2 & 24 & 17 & 18 & 5 \\
\hline 6-methyl-2-heptanone & 723 & 1 & - & & 1.2 & 0.3 & 4 & 1 & 20 & 3 \\
\hline 5-methyl-2-heptanone & 725 & 1.3 & 0. & & 2 & 1 & 9 & 3 & 52 & 4 \\
\hline 3-hydroxy-2-butanone & 727 & 251 & 89 & & 264 & 101 & 272 & 86 & 281 & 27 \\
\hline 1-hydroxy-2-propanone & 733 & 21 & 12 & & 45 & 15 & 85 & 12 & 31 & 5 \\
\hline 6-methyl-5-hepten-2-one & 742 & 21 & 2 & & 25 & 7 & 29 & 12 & 35 & 8 \\
\hline cyclopentanone & 748 & 32 & 2 & & 39 & 13 & 47 & 9 & 64 & 21 \\
\hline \multicolumn{11}{|l|}{ Class 2 - acids } \\
\hline 2-methyl-propanoic acid & 752 & 2 & 0 & & 20 & 4 & 18 & 2 & 13 & 3 \\
\hline 2-methyl-hexanoic acid & 768 & 6 & 2 & & 42 & 7 & 46 & 7 & 71 & 16 \\
\hline 3-methyl-butanoic acid & 756 & 156 & 25 & & 87 & 8 & 34 & 8 & 50 & 13 \\
\hline Hexanoic acid & 772 & 12 & 3 & & 20 & 6 & 21 & 12 & 10 & 2 \\
\hline \multirow{2}{*}{ Compounds } & \multicolumn{8}{|c|}{ Uninoculated Tsire } & \multirow{2}{*}{$P$-value } & \multirow{2}{*}{ MI } \\
\hline & SD1 & StdD & \begin{tabular}{|l|l|} 
SD2 \\
\end{tabular} & StdD & \begin{tabular}{|l|l|} 
SD3 \\
\end{tabular} & StdD & SD4 & StdD & & \\
\hline \multicolumn{11}{|l|}{ Class 1-Ketones } \\
\hline Acetone & 5852 & 43 & 5574 & 116 & 5574 & 321 & 5404 & 373 & 0.002 & 1 \\
\hline 3-methyl-2-butanone & 9 & 3 & 35 & 13 & 50 & 10 & 53 & 9 & 0.0004 & 2 \\
\hline Methyl-isobutyl-ketone & 0.93 & 0 & 10 & 3 & 29 & 3 & 47 & 9 & 0.0004 & 2 \\
\hline 2-butanone & 539 & 12 & 732 & 103 & 842 & 101 & 1431 & 108 & 0.035 & 2 \\
\hline 2,3-butanedione & 514 & 98 & 451 & 75 & 351 & 45 & 367 & 43 & 0.003 & 1 \\
\hline 3-methyl-2-pentanone & 9.37 & 0.3 & 20 & 9 & 66 & 17 & 77 & 9 & 0.0016 & 2 \\
\hline 5-methyl-2-hexanone & 80 & 13 & 89 & 23 & 93 & 18 & 126 & 16 & 0.019 & 2 \\
\hline 2-hexanone & 24 & 7 & 22 & 5 & 21 & 3 & 21 & 2 & 0.012 & 1,2 \\
\hline 2,5-Hexanedione & 91 & 27 & 167 & 31 & 251 & 65 & 452 & 98 & 0.0021 & 2 \\
\hline 2-heptanone & 3 & 1 & 38 & 18 & 108 & 33 & 120 & 12 & 0.0013 & 2 \\
\hline 2-octanone & 6 & 1 & 12 & 5 & 24 & 9 & 37 & 4 & 0.002 & 1 \\
\hline 6-methyl-2-heptanone & 0.38 & 0 & 5 & 1 & 24 & 14 & 34 & 6 & 0.001 & 2 \\
\hline 5-methyl-2-heptanone & 2 & 1 & 15 & 4 & 50 & 21 & 76 & 10 & 0.0005 & 2 \\
\hline 3-hydroxy-2-butanone & 262 & 92 & 321 & 103 & 461 & 122 & 519 & 97 & 0.007 & 2 \\
\hline 1-hydroxy-2-propanone & 7 & 2 & 16 & 4 & 55 & 23 & 31 & 9 & 0.031 & 2 \\
\hline 6-methyl-5-hepten-2-one & 22 & 5 & 21 & 7 & 40 & 13 & 62 & 11 & 0.0014 & 2 \\
\hline Cyclopentanone & 33 & 10 & 41 & 5 & 54 & 11 & 71 & 14 & 0.073 & 2 \\
\hline \multicolumn{11}{|l|}{ Class 2 - Acids } \\
\hline 2-methyl-propanoic acid & 0.8 & 0 & 16 & 2 & 18 & 3 & 12 & 2 & 0.01 & 2 \\
\hline 2-methyl-hexanoic acid & 4 & 3 & 52 & 5 & 112 & 28 & 62 & 12 & 0.003 & 2 \\
\hline 3-methyl-butanoic acid & 156 & 12 & 136 & 18 & 112 & 28 & 63 & 13 & 0.036 & 2 \\
\hline Hexanoic acid & 6 & 1 & 7 & 2 & 9 & 1 & 12 & 5 & 0.281 & 1,2 \\
\hline
\end{tabular}


Total area units $\left(\mathrm{x10}^{4}\right)$ of aromatic/cyclic hydrocarbon,

Table 2 nitrogenous and alcohol compounds in Tsire

\begin{tabular}{|c|c|c|c|c|c|c|c|c|c|}
\hline \multirow{2}{*}{ Compounds } & \multirow{2}{*}{ RI } & \multicolumn{8}{|c|}{ Tsire inoculated with $P$. acidilactici FLE07 } \\
\hline & & SD1 & StdD & SD2 & StdD & SD3 & StdD & SD4 & StdD \\
\hline \multicolumn{10}{|l|}{ Class 3-Aromatic/cyclic } \\
\hline Cyclopentene & $<600$ & 15 & 2 & 24 & 3 & 27 & 13 & 125 & 20 \\
\hline $\begin{array}{l}\text { 1-pentyl-propyl- } \\
\text { Cyclopropane }\end{array}$ & 742 & 7 & 1 & 4 & 2 & 3 & 0 & 4 & 1 \\
\hline Ethylbenzene & 747 & 13 & 3 & 8 & 2 & 3 & 0.64 & 3 & 0.33 \\
\hline $\begin{array}{l}\text { 2-methoxy-2-propenyl- } \\
\text { Benzene }\end{array}$ & 754 & 41 & 5 & 35 & 7 & 32 & 9 & 24 & 5 \\
\hline O-xylene & 756 & 8 & 1 & 5 & 1 & 3 & 0.79 & 3 & 0.57 \\
\hline $\begin{array}{l}\text { Tetramethyltricyclo- } \\
\text { Undec-2-ene }\end{array}$ & $>1000$ & 10 & 2 & 10 & 2 & 8 & 1 & 9 & 0 \\
\hline Hexamethyl-cyclotrisiloxane & $>1000$ & 7 & 2 & 8 & 2 & 6 & 3 & 7 & 0 \\
\hline \multicolumn{10}{|l|}{ Class 4-nitrogenous } \\
\hline 1-methyl-1h-pyrrole & 761 & 99 & 23 & 86 & 7 & 75 & 8 & 58 & 15 \\
\hline 3-methyl-butanenitrile & 873 & 14 & 4 & 12 & 6 & 11 & 3 & 9 & 1 \\
\hline 2-methyl-pyrazine & 881 & 7 & 2 & 11 & 1 & 14 & 2 & 37 & 2 \\
\hline Trimethyl-pyrazine & 903 & 1017 & 19 & 879 & 89 & 724 & 92 & 584 & 198 \\
\hline Tetramethyl-pyrazine & 910 & 175 & 23 & 138 & 37 & 52 & 8 & 31 & 8 \\
\hline $\begin{array}{l}\text { 3-ethyl-2,5-dimethyl- } \\
\text { Pyrazine }\end{array}$ & 921 & 4 & 1 & 5 & 0 & 5 & 2 & 12 & 2 \\
\hline 2,5-dimethyl-pyrazine & 954 & 48 & 9 & 149 & 62 & 225 & 34 & 1760 & 143 \\
\hline 2,3-dimethyl-pyrazine & 962 & 34 & 5 & 27 & 4 & 16 & 2 & 16 & 5 \\
\hline \multicolumn{10}{|l|}{ Class 5 -alcohols } \\
\hline 1-propanol & 641 & 2 & 0 & 3 & 0 & 4 & 0 & 8 & 4 \\
\hline 2,6-dimethyl-4-heptanol & 645 & 3 & 1 & 6 & 1 & 10 & 2 & 13 & 4 \\
\hline 1-pentanol & 676 & 27 & 4 & 16 & 2 & 6 & 2 & 5 & 2 \\
\hline 3-methyl-1-butanol & 701 & 14 & 2 & 21 & 4 & 41 & 10 & 325 & 28 \\
\hline 4-methyl-2-hexanol & 729 & 15 & 5 & 29 & 8 & 27 & 3 & 46 & 13 \\
\hline 3-methyl-3-buten-1-ol & 732 & 1 & 0 & 4 & 1 & 13 & 3 & 13 & 1 \\
\hline 1-octen-3-ol & 741 & 53 & 7 & 57 & 18 & 48 & 9 & 39 & 11 \\
\hline 3-methyl-2-butanol & 748 & 3 & 1 & 4 & 1 & 9 & 4 & 33 & 12 \\
\hline P-menth-1-en-8-ol & 749 & 10 & 1 & 8 & 1 & 7 & 1 & 7 & 1 \\
\hline Tricyclo(1,5)dec-5-en-8-ol & 759 & 25 & 6 & 15 & 2 & 10 & 2 & 6 & 1 \\
\hline Phenylethyl-alcohol & 792 & 2 & 0 & 3 & 1 & 3 & 0 & 33 & 9 \\
\hline Ursane-3,16-diol & 812 & 17 & 7 & 11 & 4 & 10 & 6 & 23 & 5 \\
\hline
\end{tabular}


Table 2

(continuation)

\begin{tabular}{|c|c|c|c|c|c|c|c|c|c|c|}
\hline \multirow[t]{2}{*}{ Compounds } & \multicolumn{8}{|c|}{ Uninoculated Tsire } & \multirow{2}{*}{$P$-value } & \multirow{2}{*}{ MI } \\
\hline & SD1 & StdD & SD2 & StdD & SD3 & StdD & SD4 & StdD & & \\
\hline \multicolumn{11}{|l|}{ Class 3-Aromatic/cyclic } \\
\hline Cyclopentene & 77 & 12 & 79 & 9 & 76 & 22 & 174 & 17 & 0.005 & 2 \\
\hline $\begin{array}{l}\text { 1-pentyl-propyl- } \\
\text { Cyclopropane }\end{array}$ & 7 & 2 & 3 & 1 & 7 & 2 & 9 & 2 & 0.0061 & 2 \\
\hline Ethylbenzene & 12 & 2 & 9 & 3 & 6 & 0.63 & 6 & 1 & $<0.001$ & 2 \\
\hline $\begin{array}{l}\text { 2-methoxy-2-propenyl- } \\
\text { Benzene }\end{array}$ & 40 & 12 & 48 & 9 & 50 & 11 & 71 & 5 & 0.004 & 2 \\
\hline O-xylene & 8 & 3 & 6 & 2 & 4 & 0.87 & 4 & 0.63 & 0.005 & 2 \\
\hline $\begin{array}{l}\text { Tetramethyltricyclo- } \\
\text { Undec-2-ene }\end{array}$ & 8 & 2 & 8 & 3 & 9 & 2 & 9 & 3 & 0.2719 & 2 \\
\hline $\begin{array}{l}\text { Hexamethyl- } \\
\text { cyclotrisiloxane }\end{array}$ & 3 & 1 & 5 & 2 & 6 & 2 & 12 & 3 & 0.0331 & 2 \\
\hline \multicolumn{11}{|l|}{ Class 4-nitrogenous } \\
\hline 1-methyl-1h-pyrrole & 98 & 21 & 103 & 31 & 113 & 14 & 144 & 28 & 0.004 & 2 \\
\hline 3-methyl-butanenitrile & 14 & 2 & 13 & 5 & 16 & 8 & 21 & 3 & 0.0017 & 1 \\
\hline 2-methyl-pyrazine & 11 & 2 & 17 & 5 & 51 & 11 & 73 & 3 & 0.0004 & 2 \\
\hline Trimethyl-pyrazine & 1020 & 37 & 987 & 29 & 975 & 184 & 760 & 35 & 0.03 & 2 \\
\hline Tetramethyl-pyrazine & 176 & 18 & 156 & 39 & 129 & 10 & 46 & 9 & 0.024 & 2 \\
\hline $\begin{array}{l}\text { 3-ethyl-2,5-dimethyl- } \\
\text { pyrazine }\end{array}$ & 4 & 0 & 9 & 4 & 39 & 9 & 33 & 3 & 0.0728 & 2 \\
\hline 2,5-dimethyl-pyrazine & 68 & 12 & 820 & 123 & 2462 & 128 & 3783 & 210 & 0.0003 & 2 \\
\hline 2,3-dimethyl-pyrazine & 31 & 13 & 29 & 5 & 22 & 2 & 21 & 0 & 0.013 & 2 \\
\hline \multicolumn{11}{|l|}{ Class 5 -alcohols } \\
\hline 1-propanol & 2 & 0 & 5 & 2 & 13 & 6 & 18 & 10 & 0.0009 & 1 \\
\hline 2,6-dimethyl-4-heptanol & 4 & 1 & 10 & 2 & 19 & 4 & 27 & 7 & 0.004 & 2 \\
\hline 1-pentanol & 27 & 6 & 19 & 2 & 10 & 2 & 8 & 2 & 0.005 & 1 \\
\hline 3-methyl-1-butanol & 19 & 4 & 33 & 11 & 910 & 40 & 1455 & 300 & 0.0035 & 2 \\
\hline 4-methyl-2-hexanol & 14 & 2 & 22 & 12 & 42 & 4 & 59 & 6 & $<0.0001$ & 2 \\
\hline 3-methyl-3-buten-1-ol & 1 & 0 & 6 & 1 & 13 & 1 & 20 & 2 & 0.0001 & 2 \\
\hline 1-octen-3-ol & 53 & 8 & 59 & 11 & 64 & 10 & 97 & 19 & 0.019 & 2 \\
\hline 3-methyl-2-butanol & 2 & 0 & 16 & 7 & 27 & 6 & 35 & 10 & 0.0005 & 2 \\
\hline P-menth-1-en-8-ol & 9 & 1 & 7 & 1 & 9 & 3 & 11 & 3 & 0.0189 & 2 \\
\hline $\begin{array}{l}\text { Tricyclo(1,5)dec-5-en- } \\
8 \text {-ol }\end{array}$ & 25 & 3 & 21 & 6 & 14 & 2 & 9 & 1 & 0.017 & 2 \\
\hline Phenylethyl-alcohol & 2 & 1 & 3 & 1 & 19 & 4 & 36 & 5 & 0.0004 & 2 \\
\hline Ursane-3,16-diol & 6 & 1 & 17 & 3 & 13 & 4 & 20 & 3 & 0.009 & 2 \\
\hline
\end{tabular}

Each value is mean of three replicates of samples; SD1, storage day 1; SD2, storage day 2; SD3, storage day 3; SD4, storage day 4; StdD, standard deviation; $P$-value, probability value; RI, retention index; MI, method of identification; 1, Identification using authentic standards; 2, Identification using retention indices from the literature and their mass spectra with the NIST mass spectral library 
The total area units (TAUs) of the class of ketone compounds identified in the meat product are shown in Table 1. The volatiles acetone, 2-butanone, 2,3-butanedione, 3hydroxy-2-butanone, 2-hexanone, 2-heptanone and 1-hydroxy-2-propanone were among the prominent ketone compounds which recorded significant differences $(p<0.05)$ in their TAUs between the IS and UC samples. Some of the ketone volatiles have been noted to play important roles in sensory characteristics of meat products [7]. One of the important ketone compound was 3-hydroxy-2-butanone (acetoin), a product of degradation due to maillard reaction; its identification from meat products has been reported $[3,16]$. Presence of this compound especially in relatively high concentration may cause spoilage of food [17]. Lower values of TAUs of acetoin $(p=0.0004)$ were recorded in IS than UC samples, indicating that inoculation of the meat product with starter culture had significant effect on the compound; this observation may help enhance shelf life of the product. The reduced TAU of acetoin in the IS sample may be attributed to possible antioxidative property of $P$. acidilactici FLE07 used as starter culture $[18,19,20]$, which may bring about reduction of undesirable volatile compounds in meat products. Acetoin has been reported as a spoilage molecule associated with in meat products during storage [21].

The compounds, 2-hexanone, 2-heptanone and 2-butanone were among the ketone compounds identified in the present study, and they have been noted as contributors to off flavour development in meat products [22]; however their TAUs were lower $(\mathrm{p}<0.05)$ in the IS samples than UC. This may therefore translate that they are present in reduced concentration in IS than UC samples, indicating that there may be reduction of off flavour development in the meat product inoculated with the starter culture. Another ketone compound identified in this study was 2,3-butanedione (diacetyl), which has been reported as a product of lactose and citrate metabolism by the action of bacteria, especially LAB [23]. The occurrence of the compound in Tsire is in support of a similar report by Huan et al. [24] in a research investigation during storage of a Chinese meat product - Jinhua ham. Diacetyl may be of technological importance as it possesses anti-microbial properties against many unwanted microorganisms, especially the spoilage types, in foods [25].

The volatile compounds in class 2 comprised of 2-methyl-propanoic acid, hexanoic acid, 3-methyl-butanoic acid and 2-methyl-hexanoic acid, all of which had higher TAUs in IS than UC (Table 1). Significant difference $(\mathrm{p}<0.05)$ was recorded in the acids of IS and UC, with the exception of hexanoic acid. Lower values of TAUs were recorded for the acids $(p<0.05)$ in IS than $\mathrm{UC}$, and this may be of significance as a result of possible association of certain acids, especially 3-methyl-butanoic acid, butanoic acid (and some of its derivatives) with meat spoilage [17]

The seven volatile compounds of aromatic/cyclic hydrocarbons belonging to class 3 compounds in IS were significantly different $(p<0.05)$ from those of UC (Table 2), with the only exception of tetramethyltricyclo-undec-2-ene. They have reduced TAUs in the IS samples compared to UC, indicating possible influence of the starter culture. One of the compounds belonging to class 3 was ethylbenzene, which presence in the meat product may be very significant as it may be associated with spoilage of meat and fish $[17,26]$. The reduced values of TAUs of the compound in the IS samples is therefore desirable towards possible reduction of spoilage in the meat product. The nitrogenous compounds (class 4) consisted mostly of pyrazines, which are regarded as products of maillard reactions; their formation in meat products could be attributed to application of heat and salting during processing [26]. Contribution of pyrazines to development of desirable sensory characteristics of grilled and roasted meat has been reported [16]. The identification of nitrogenous compounds, 2,3-dimethyl-pyrazine and tetramethyl-pyrazine in meat products was observed by Gianelli et al. [16], thus supporting their occurrence in Tsire in the present study. The class 5 volatile compounds consisted of twelve alcohol compounds (Table 2), most of which recorded lower values of TAUs $(\mathrm{p}<0.02)$ in IS samples than UC. Among 
these compounds, 1-octen-3-ol and 3-methyl-1-butanol have been noted as spoilage molecules in meat products [21]. The lower values of TAUs of these compounds in IS samples than UC may thus indicate possible extension in shelf life of the former over the latter.

The chart of PCA carried out on the volatile compounds during storage of Tsire samples inoculated with starter culture is presented in Figure 2. At the upper portion in the left hand side of the chart are represented the principal components associated with the meat samples on storage day 1 (Sd1). The principal components on Sd1 were composed of 2,3-dimethyl-pyrazine, o-xylene, p-menth-1-en-8-ol, ethylbenzene, hexamethylcyclotrisiloxane, 3-methyl-butanoic acid, 1,2-diepoxyhexadecane, 1-pentyl-2-propylcyclopropane, tetramethyltricyclo-undec-2-ene, and 3-methyl-butanenitrile, which represent $15.6 \%$ of the total volatile compounds (TVCs) in the meat product. On Sd2 (lower portion of the left hand side), the principal components included octane, 2-hexanone, 1-methyl-1hpyrrole, 2,3-butanedione, acetone, 1-pentanol, (e)-3-dodecene, heptane, trimethyl-pyrazine, 2-pentyl-furan, tricycle(1,5)dec-5-en-8-ol, tetramethyl-pyrazine, 2-methoxy-2-propenylbenzene and 5-methyl-2-hexanone, representing $21.9 \%$ of TVCs. A major cluster was formed on $\mathrm{Sd} 2$ consisting mainly of ketones, alcohols and pyrazines, suggesting that these compounds were the major ones associated with the product on second day of storage. On $\mathrm{Sd} 3$ (lower portion in the right hand side of chart), the principal components identified were 3-methyl-3-buten-1-ol, 2-octanone, 2-methyl-propanoic acid, 1-hydroxy-2-propanone, nonanal and hexanoic acid, forming $9.4 \%$ of TVCs. Twenty two principal components (representing $34.4 \%$ of TVCs) occurred on Sd4 (upper portion in the right hand side of chart), belonging mainly to alcohols, ketones, nitrogenous compounds, acids and pyrazines.

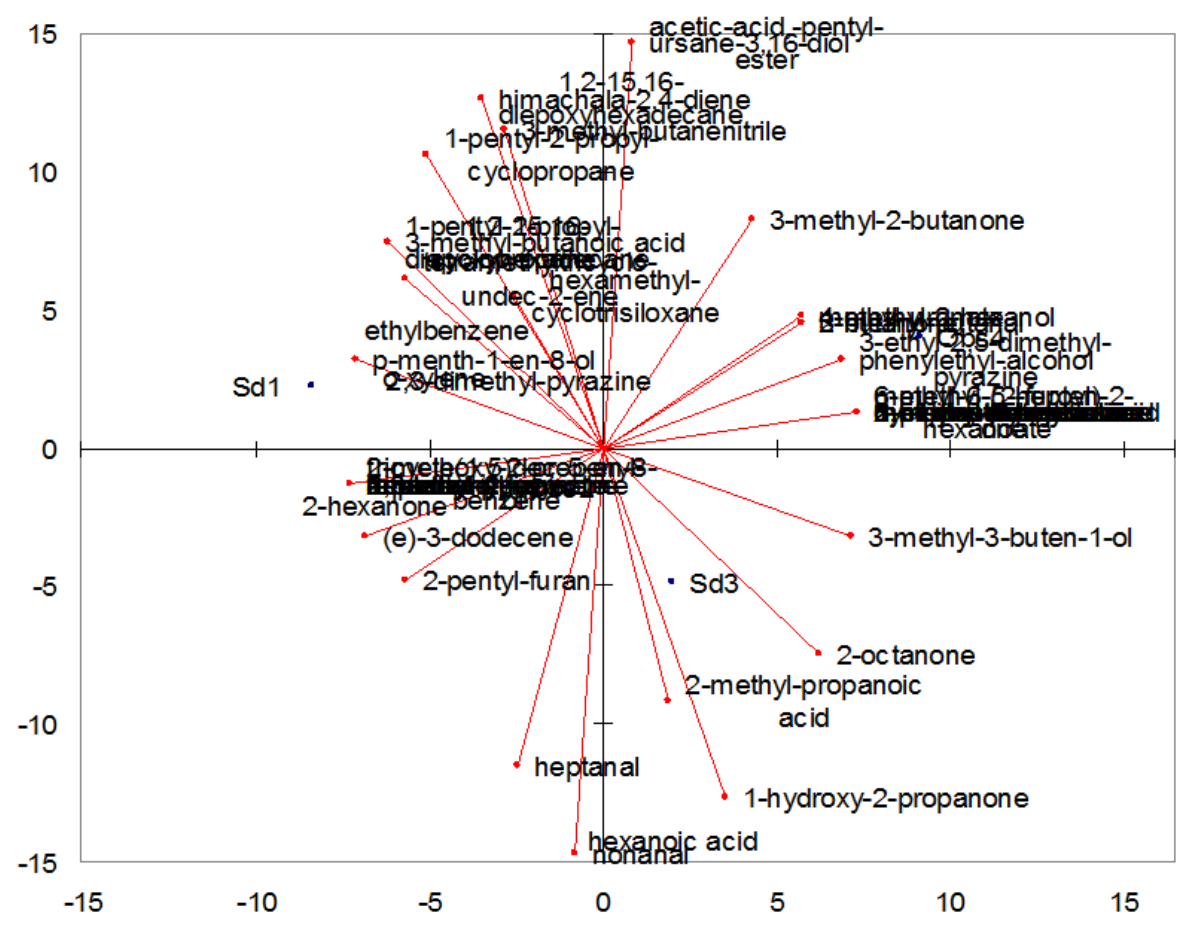

Figure 2. Principal component analysis of volatiles and SPME-GCMS peak area data from the headspace of inoculated $T$ sire

Sd1, Storage day 1; Sd2, Storage day 2; Sd3, Storage day 3; Sd4, Storage day 4. 
The mean quantities $(\mu \mathrm{g} / \mathrm{g})$ of some volatile molecules identified in the meat product are shown in Table 3. Result indicated that compounds which have been regarded as spoilage indicators of meat had higher TAUs in UC than IS samples $(p<0.05)$, suggesting the influence of the starter culture used. The compounds included 3-hydroxy-2-butanone, heptanal, nonanal, 2-butanone, 1-octen-3-ol and 3-methyl-butanoic acid, some of which had been noted earlier.

Table 3

Mean quantities $(\mu \mathrm{g} / \mathrm{g})$ of some head space compounds in Tsire

\begin{tabular}{|l|r|r|r|r|r|r|r|r|r|}
\hline \multirow{2}{*}{ Compounds } & \multirow{2}{*}{ RI } & \multicolumn{6}{|c|}{ Tsire inoculated with P. acidilactici FLE07 } \\
\cline { 3 - 10 } & & SD1 & StdD & SD2 & StdD & SD3 & StdD & SD4 & StdD \\
\hline 2-butanone & 618 & 38.52 & 2.78 & 38.47 & 4.84 & 42.17 & 9.26 & 47.39 & 11.93 \\
\hline 2,3-butanedione & 621 & 37.23 & 11.02 & 29.83 & 5.4 & 30.03 & 5.82 & 16.73 & 3.29 \\
\hline 2-hexanone & 699 & 1.9 & 0.51 & 1.76 & 0.25 & 1.7 & 0.42 & 1.21 & 3 \\
\hline 3-methy-1-butanol & 701 & 1.26 & 0.54 & 1.82 & 0.37 & 3.37 & 0.09 & 29.93 & 7.26 \\
\hline 2-heptanone & 719 & 0.23 & 0.01 & 1.16 & 0.09 & 1.65 & 0.39 & 2.17 & 0.82 \\
\hline Heptanal & 725 & 1.62 & 0.08 & 0.58 & 0.03 & 0.57 & 0.07 & 0.49 & 0.11 \\
\hline $\begin{array}{l}\text { 3-hydroxy-2-butanone } \\
\text { (acetoin) }\end{array}$ & 727 & 23.26 & 9.18 & 25.01 & 4.19 & 25.92 & 7.02 & 27.28 & 5.4 \\
\hline 1-octen-3-ol & 741 & 2.36 & 0.19 & 2.41 & 0.24 & 1.98 & 0.08 & 2.13 & 0.17 \\
\hline Ethylbenzene & 747 & 1.22 & 0.18 & 0.69 & 0.04 & 0.31 & 0.07 & 0.32 & 0.01 \\
\hline 3-methyl-butanoic acid & 756 & 2.31 & 0.77 & 1.29 & 0.14 & 0.93 & 0.04 & 0.77 & 0.12 \\
\hline Nonanal & 982 & 1.59 & 0.09 & 1.62 & 0.42 & 1.39 & 0.41 & 0.89 & 0.02 \\
\hline
\end{tabular}

\begin{tabular}{|c|c|c|c|c|c|c|c|c|c|c|}
\hline \multirow{2}{*}{ Compounds } & \multicolumn{8}{|c|}{ Uninoculated Tsire } & \multirow{2}{*}{ 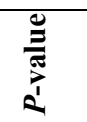 } & \multirow{2}{*}{ MI } \\
\hline & SD1 & StdD & SD2 & StdD & SD3 & StdD & SD4 & StdD & & \\
\hline 2-butanone & 38.51 & 9.28 & 47.83 & 7.31 & 49.15 & 8.97 & 59.53 & 9.28 & 0.035 & 2 \\
\hline 2,3-butanedione & 37.19 & 5.47 & 33.89 & 10.29 & 30.95 & 12.4 & 31.28 & 8.35 & 0.013 & 1 \\
\hline 2-hexanone & 1.87 & 0.24 & 1.85 & 0.71 & 1.83 & 0.61 & 1.84 & 0.12 & 0.007 & 1,2 \\
\hline 3-methyl-1-butanol & 1.28 & 0.08 & 1.97 & 0.28 & 50.17 & 10.3 & 61.29 & 14.29 & 0.005 & 2 \\
\hline 2-heptanone & 0.22 & 0.03 & 2.27 & 0.93 & 10.41 & 2.19 & 12.86 & 0.84 & 0.009 & 2 \\
\hline Heptanal & 1.6 & 0.18 & 1.89 & 0.55 & 2.43 & 0.82 & 5.86 & 0.93 & 0.008 & 1 \\
\hline $\begin{array}{l}\text { 3-hydroxy-2-butanone } \\
\text { (acetoin) }\end{array}$ & 23.75 & 4.5 & 29.72 & 10.2 & 34.12 & 2.93 & 37.84 & 4.72 & 0.005 & 2 \\
\hline 1-octen-3-ol & 2.42 & 0.26 & 2.97 & 0.36 & 3.21 & 1.02 & 4.32 & 0.63 & 0.008 & 2 \\
\hline Ethylbenzene & 0.93 & 0.03 & 2.92 & 0.07 & 3.1 & 0.74 & 3.96 & 1.01 & 0.01 & 2 \\
\hline 3-methyl-butanoic acid & 2.32 & 0.09 & 2.83 & 1.29 & 2.94 & 0.91 & 2.89 & 0.72 & 0.027 & 2 \\
\hline Nonanal & 1.6 & 0.16 & 2.43 & 0.34 & 2.94 & 1.04 & 3.72 & 0.65 & 0.005 & 1 \\
\hline
\end{tabular}

Each value is mean of three replicates of samples; SD1, storage day 1; SD2, storage day 2; SD3, storage day 3; SD4, storage day 4; $\mathrm{StdD}$, standard deviation; $P$-value, probability value; RI, retention index; MI, method of identification; 1, Identification using authentic standards; 2, Identification using retention indices from the literature and their mass spectra with the NIST mass spectral library 
Result of sensory study carried out on the meat samples during storage is presented in Table 4. It was observed that IS samples recorded higher mean scores by the panelists than $\mathrm{UC}(\mathrm{p}<0.05)$ from $24 \mathrm{~h}$ of storage in the sensory properties of aroma, appearance, tenderness and taste. The IS samples also recorded higher preference than UC in term of general acceptability $(\mathrm{p}<0.05)$. The result of sensory study corroborates the report of CaloMata et al. [27] who noted that LAB cultures may be used to develop desirable sensory characteristic properties in food products. The number of panelist who allocated scores higher than 5 to the meat samples decreased gradually as storage period progressed, the decrease was however more pronounced in UC than IS samples. Result further indicated that IS samples recorded higher acceptability by consumers than $\mathrm{UC}(\mathrm{p}<0.05)$.

Result of sensory study on the Tsire samples during storage

Table 4

\begin{tabular}{|c|c|c|c|c|c|c|c|}
\hline $\begin{array}{l}\cong \\
\tilde{\omega}\end{array}$ & $\frac{\frac{\tilde{e}}{2}}{\bar{E}}$ & 苞 & 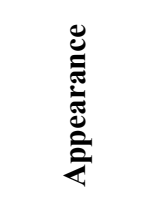 & 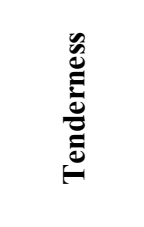 & $\begin{array}{c}\frac{\pi}{\sigma} \\
\underset{\sigma}{\sigma}\end{array}$ & 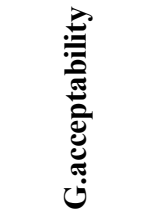 & 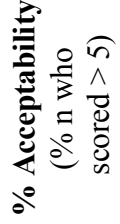 \\
\hline 0 & $\mathrm{~F}$ & $7.5 \pm 1.29$ & $6.9 \pm 0.18$ & $7.8 \pm 0.76$ & $7.6 \pm 2.01$ & $8.1 \pm 1.29$ & 100 \\
\hline \multirow[t]{2}{*}{24} & IS & $7.3 \pm 1.20$ & $7.0 \pm 0.92$ & $7.4 \pm 0.87$ & $7.1 \pm 2.30$ & $7.5 \pm 2.17$ & 90 \\
\hline & US & $6.9 \pm 0.98$ & $6.1 \pm 1.28$ & $6.2 \pm 1.07$ & $6.7 \pm 0.29$ & $6.9 \pm 1.55$ & 75 \\
\hline \multirow[t]{2}{*}{48} & IS & $7.0 \pm 2.08$ & $6.5 \pm 1.33$ & $6.9 \pm 0.94$ & $6.8 \pm 0.67$ & $6.4 \pm 1.36$ & 87 \\
\hline & US & $5.8 \pm 0.93$ & $5.3 \pm 0.77$ & $5.1 \pm 1.25$ & $5.3 \pm 1.33$ & $5.2 \pm 0.55$ & 59 \\
\hline \multirow[t]{2}{*}{72} & IS & $6.2 \pm 1.20$ & $6.0 \pm 0.88$ & $6.3 \pm 1.29$ & $6.1 \pm 0.82$ & $5.9 \pm 0.72$ & 74 \\
\hline & US & $4.7 \pm 0.73$ & $4.2 \pm 0.15$ & $4.3 \pm 1.08$ & $3.9 \pm 0.73$ & $3.8 \pm 0.88$ & 36 \\
\hline
\end{tabular}

Each value is mean of three replicates of samples; SP, Storage period; $F$, freshly prepared Tsire; IS, Tsire samples inoculated with starter culture; US, uninoculated Tsire samples; G.acceptability, General acceptability; $n$, number of panelists

From the results of this study, it was concluded that inoculation of Tsire with $P$. acidilactici FLE07 as starter culture had significant and desirable influence on the associated volatile compounds and sensory properties. This observation is in support of previous studies which reported impact of LAB cultures on volatile compounds of meat products. It was further concluded that the use of $P$. acidilactici FLE07 may contribute to extended shelf life of Tsire during storage as a result of reduction recorded in some of the known spoilage molecules. Suitable LAB starter cultures may therefore be applied towards promoting sensory quality development and availability of the traditional meat product beyond the day of production.

Acknowledgement. Author expresses gratitude to the Division of Food Sciences, University of Nottingham, UK where certain aspects of this study were carried out. The financial support provided by The Federal Polytechnic, Offa, Kwara State, Nigeria is appreciated. 


\section{References}

1. Olaoye O.A. (2015), A preliminary study on the effect of storage period on flavour profile and consumers' acceptability of tsire, a Nigerian stick meat, AASCIT Journal of Chemistry, 2, pp. 77-84.

2. Olaoye O.A., Dodd C.E.R. (2010), Evaluation of bacteriocinogenic Pediococcus acidilactici as protective culture in the preservation of $t$ sire, a traditional Nigerian stick meat, Journal of Food Safety, 30, pp. 867-888.

3. Olaoye O.A. (2016), Changes in physicochemical properties and volatiles of pork balangu as possible indicators of spoilage during ambient temperature storage, Journal of Food Processing and Preservation, 40, pp. 473-482.

4. Nedelcheva P., Denkova Z., Denev P., Slavchev A., Krastanov, A. (2010) Probiotic strain Lactobacillus plantarum NBIMCC 2415 with antioxidant activity as a starter culture in the production of dried fermented meat products, Biotechnology and Biotechnological Equipment, 24(1), pp. 1624-1630.

5. Olaoye O.A., Onilude A.A., Idowu O.A. (2011), Microbiological profile of goat meat inoculated with lactic acid bacteria cultures and stored at $30^{\circ} \mathrm{C}$ for 7 days. Food and Bioprocess Technology, 4, pp. 312-319.

6. Fernández M., Martín A., Benito M.J., Casquete R., Recio I., Córdoba M.D. (2016), Influence of starter cultures on the generation of antioxidant nitrogen compounds in Iberian dry-fermented sausages, International Journal of Food Science and Technology, 51, pp. 435-443.

7. Lorenzo J.M., Gómez M., Purriños L., Fonseca S. (2016), Effect of commercial starter cultures on volatile compound profile and sensory characteristics of dry - cured foal sausage, Journal of the Science of Food and Agriculture, 96, pp. 1194-1201.

8. Olaoye O.A., Onilude A.A., Dodd C.E.R. (2008), Identification of Pediococcus spp. from beef and evaluation of their lactic acid production in varying concentrations of different carbon sources, Advances in Natural and Applied Sciences, 2, pp. 197-207.

9. Suwanjinda D., Eames C., Panbangred W. (2007), Screening of lactic acid bacteria for bacteriocins by microbiological and PCR methods, Biochemistry and Molecular Biology Education, 35, pp. 364-369.

10. Ercolini D., Moschetti G., Blaiotta G., Coppola S. (2001), Behaviour of variable V3 region from $16 \mathrm{~S}$ rDNA of important lactic acid bacteria in denaturing gradient gel electrophoresis, Current Microbiology, 42, pp. 199-202.

11. Goranov B., Denkova R., Teneva D., Denkova Z., Popova P. (2015), Molecular-genetic identification of Lactobacillus strains, isolated from homemade yoghurt. Ukrainian Food Journal, 4(1), 67-76.

12. Olaoye O.A., Onilude A.A. (2010), Investigation on the potential use of biological agents in the extension of fresh beef in Nigeria, World Journal of Microbiology and Biotechnology, 26, pp. 1445-1454.

13. Liu C., Zhang J., Zhou Z., Hua Z., Wan H., Xie Y., Wang Z., Deng L. (2013), Analysis of volatile compounds and identification of characteristic aroma components of Toona sinensis (A. Juss.) Roem. using GC-MS and GC-O, Food Nutritional Sciences, 4, pp. 305-314.

14. Fadel H.H.M., Samad A.A., Kobeasy M.I., Mageed M.A., Lotfy S.N. (2015), Flavour quality and stability of an encapsulated meat-like process flavouring prepared from soybean based acid hydrolyzed protein, International Journal of Food Processing and Technology, 2, pp. 17-25. 
15. Sanchez-Del-Pulgar J., Roldan M., Ruiz-carrascal J. (2013), Volatile compounds profile of sous-vide cooked pork cheeks as affected by cooking conditions (vacuum packaging temperature and time), Molecules, 18, pp. 12538-12547.

16. Gianelli M.P., Salazar V.., Mojica L., Friz M. (2012), Volatile compounds present in traditional meat products (Charqui and Longaniza sausage) in Chile, Brazilian Archives of Biology and Technology, 55, pp. 603-612.

17. Wierda R.L., Fletcher G., Xu L., Dufour J.P. (2006), Analysis of volatile compounds as spoilage indicators in fresh king salmon (Oncorhynchus tshawytscha) during storage using SPME-GC-MS, Journal of Agriculture and Food Chemistry, 54, pp. 8480-8490.

18. Kuda T., Kawahara M., Nemoto M., Takahashi H., Kimura B. (2014), In vitro antioxidant and anti-inflammation properties of lactic acid bacteria isolated from fish intestines and fermented fish from the Sanriku Satoumi region in Japan, Food Research International, 64, pp. 248-255.

19. Barbosa J., Borges S., Teixeira P. (2016), Pediococcus acidilactici as a potential probiotic to be used in food industry, International Journal of Food Science and Technology, 50, pp. 1151-1157.

20. Ilavenil S., Vijayakumar M., Kim, D.H., Arasu M.V., Park H.S., Ravikumar S., Choi K.C. (2016), Assessment of probiotic, antifungal and cholesterol lowering properties of Pediococcus pentosaceus KCC - 23 isolated from Italian ryegrass, Journal of the Science of Food and Agriculture, 96, pp. 593-601.

21. Casaburi A., Nasi A., Ferrocino I., DI Monaco R., Mauriello G., Villani F., Ercolini D. (2011), Spoilage-related activity of Carnobacterium maltaromaticum strains in airstored and vacuum-packed meat. Applied and Environmental Microbiology, 7, pp. 7382-7393.

22. Estevez M., Ventanas S., Cava R. (2005), Protein oxidation in frankfurters with increasing levels of added rosemary essential oil: effect on colour and texture deterioration, Journal of Food Science, 70, pp. 427-432.

23. Rivas-Cañedo A., Fernández-García E., Nuñez M. (2009), Volatile compounds in fresh meats subjected to high pressure processing: Effect of the packaging material, Meat Science, 81, pp. 321-332.

24. Huan Y.J., Zhou G.H., Zhao G.M., Xu X.L., Peng Z.Q. (2005), Changes in flavor compounds of dry-cured Jinhua ham during processing, Meat Science, 71, pp. 291299.

25. Olaoye O.A., Ubbor S.C., Agiriga A.N. (2016), In vitro assay for production of organic acids and diacetyl by Lactococcus spp. isolated from food source, Chemistry Research Journal, 1, pp. 76-84.

26. Wanga Y., Lia Y., Yanga J., Ruana J., Sun C. (2016), Microbial volatile organic compounds and their application in microorganism identification in foodstuff, $\operatorname{Tr} A C$ Trends in Analytical Chemistry, 78, pp. 1-16.

27. Calo-Mata P., Arlindo S., Boehme K., de Miguel T., Pascoal A., Barros-Velazquez J. (2008), Current applications and future trends of lactic acid bacteria and their bacteriocins for the biopreservation of aquatic food products, Food Bioprocess and Technology, 1, pp. 43-63. 